\title{
Neuro-fuzzy model for evaluating the performance of processes using transfer function
}

\author{
CHIDOZIE CHUKWUEMEKA NWOBI-OKOYE
}

Chukwuemeka Odumegwu Ojukwu University (Formerly Anambra State University), Uli, Anambra, Nigeria e-mail: cc.nwobiokoye@coou.edu.ng; chidozien@yahoo.com

MS received 21 April 2015; revised 30 May 2017; accepted 31 May 2017; published online 16 November 2017

\begin{abstract}
In this work an Adaptive Neuro-Fuzzy Inference System (ANFIS) was used to model the periodic performance of some multi-input single-output (MISO) processes, namely: brewery operations (case study 1) and soap production (case study 2) processes. Two ANFIS models were developed to model the performance of the two processes under study. The results of the study show that for brewery operations, ANFIS model 2 with a correlation coefficient of 0.9972 , as against 0.9956 for ANFIS model 1 , had a better correlation than an equivalent MAMDANI fuzzy model. On the order hand, for soap production process, ANFIS model 1 had better correlation with an equivalent MAMDANI model. Generally, there is a general agreement among the models on the periodic performance of the processes. Thus, all the models show that for the brewery, the best performance was in the period 2010-2011 and the period 2008-2009 was the worst. Similarly, for the soap production process, the best performance was in 2011 and the worst in 2012. The results show that a combination of transfer function and ANFIS could be used effectively to model process performance.
\end{abstract}

Keywords. Transfer function; neuro-fuzzy; multi-input single-output process; modelling.

\section{Introduction}

Proper process monitoring and control would be of immense benefit to any organization involved in the production of goods and services. Good process monitoring tools would help reduce downtime, reduce rejects and effectively monitor raw materials usage. An excellent statistically robust process monitoring and control tool is the transfer function modelling [1-7], which is especially useful in production processes. Transfer function modelling is a complex task, and it is especially tasking when the input is more than one. In a typical multi-input singleoutput (MISO) production process, as typified by brewing, there is variability in inputs and the output as depicted in figure 1.

The use of transfer function for modelling performance of processes and systems has been pioneered by NwobiOkoye and Igboanugo [6]. In their pioneering work, Nwobi-Okoye and Igboanugo considered only the singleinput single-output (SISO) case, as typified by power generation systems. For multi-input-single-output (MISO) systems the method developed by Nwobi-Okoye and Igboanugo fails. Such MISO systems/processes are typified by processes such as brewing and soap production as examples. The complexity of such systems requires complementing transfer function modelling with soft computing and expert system techniques of fuzzy logic and artificial neural network (ANN). By so doing, the behaviour and performance of such systems or processes could be modelled.

Fuzzy logic was developed by Zadeh [8]. Since the pioneering work of Zadeh, fuzzy logic has been applied in several fields of life. Of great importance is the application of fuzzy logic for evaluating the performance of systems and processes. Fuzzy logic was used by Ertuğrul and Karakaşoğlu [9] to evaluate the performance of firms by using financial ratios and at the same time, taking subjective judgments of decision makers into consideration. They used the method to assess the performance of 15 Turkish cement firms in the Istanbul Stock Exchange using their financial tables and determined the rankings of the firms according to their results. Seçme et al [10] used a fuzzy multicriteria decision model to evaluate and assess the performances of banks. They selected, examined, assessed and evaluated the largest five commercial banks of Turkish Banking in terms of several financial and non-financial indicators. They integrated fuzzy Analytic Hierarchy Process (FAHP) and Technique for Order Performance by Similarity to Ideal Solution (TOPSIS) methods into their model. The results they obtained showed that not only financial performance but also non-financial performance should be taken into account in a competitive environment. Chen [11] evaluated and assessed the performance of weapon systems using fuzzy arithmetic operations. He discovered that because the 


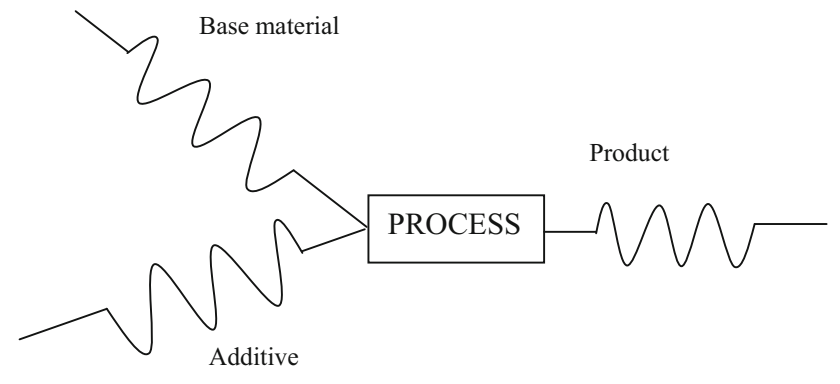

Figure 1. Schematic of the input-output relationship of a typical MISO production process.

proposed method uses simplified fuzzy arithmetic operations of fuzzy numbers rather than the complicated entropy weight calculations used in a previous research, its execution is much faster than the one presented in the previous research. Yang and Chen [12] introduced an assessment model that integrates triangular fuzzy numbers and the analytical hierarchy process to develop a fuzzy multipleattribute decision-making (FMADM) model for key quality-performance evaluation. The results they obtained from the study demonstrate that decision makers can use the flexibility of the proposed model by adjusting the confidence coefficient to express their degree of understanding with respect to the importance of each component and is also a significant contribution to quality improvement. Sadiq et al [13] used fuzzy logic to evaluate, assess and predict the performance of slow sand filters used for wastewater treatment using the uncertainties in the control parameters and processes. The results were compared with an equivalent model that uses multiple regression and was found to have performed creditably well. Yeh et al [14] developed an effective fuzzy multicriteria analysis (MA) approach to performance assessment and evaluation for urban public transport systems involving multiple criteria of multilevel hierarchies and subjective assessments of decision alternatives. The approach they developed was found to be computationally efficient, and its underlying concepts simple and comprehensible. They used a case study on ten bus companies of an urban public transport system in Taiwan to illustrate the efficiency and effectiveness of the approach. Wu [15], in his research, developed an integrated approach to rate decision alternatives using data envelopment analysis and fuzzy preference relations. There are several other works that used fuzzy for performance evaluation. Some of these works include Cheng and Lin [16] and Lin et al [17].

Effective modelling using fuzzy logic involves the development of rules that govern the fuzzy inference process. Mastering such rules is often not easy, thus necessitating the need for neural networks and intelligent systems that have very high learning ability [18]. Combining neural networks and fuzzy logic gave rise to the development of Adaptive Neuro-Fuzzy Inference System
(ANFIS). ANFIS is a modelling tool that has had a very extensive application in several fields. As a complement to fuzzy logic, ANFIS has been applied to performance evaluation and condition monitoring. Sandhu and Singh [19] used neuro-fuzzy approach to appraise the reusability of software components. The results they obtained showed that the system could be used for economical identification and retrieval of reusable software components. Hosoz et al [20] used an ANFIS model for predicting the performance of a refrigeration system with a cooling tower. Their model was used for predicting several performance indicators of the system, including the evaporation temperature, compressor power and coefficient of performance (COP). The results they obtained suggest that the ANFIS approach can be used successfully for predicting the performance of refrigeration systems with cooling towers. Wang et al [21] applied neuro-fuzzy modelling system to machine health condition prognosis. From their test results they found that the neuro-fuzzy prognostic system was very reliable and robust machine health condition predictor. They equally found that it can capture the system dynamic behaviour quickly and accurately. This research lends credence to the power of ANFIS as a performance predictor and condition monitoring tool, which could complement transfer function modelling.

The fact that transfer functions like fuzzy logic are performance assessment as well as condition and process monitoring tools, as seen in the literature before, and neural networks are excellent in mastering fuzzy logic rules means that combining the three tools would result in better process monitoring and control. This study represents an attempt to combine the accuracy, statistical robustness and precisions of transfer function modelling, the ability of fuzzy logic to deal with vagueness and uncertainty and the ability of neural networks to effectively master fuzzy logic rules to evaluate and monitor the performance of MISO processes as exemplified by the brewing and soap production processes. The investigation hubs are a local brewing company known as Consolidated Breweries PLC located at Awo Omamma, Imo State, Nigeria, and a local soap production company known as Promotex Industrial and Chemical Company Limited located at Umudim, Nnewi, Anambra State, Nigeria.

\section{Theoretical brief}

\subsection{Multiple-input transfer function models}

In terms of the impulse response weights $v(B)$, the discrete transfer function model can be represented as [1]

$$
Y_{t}=v(B) X_{t-b}+N_{t} .
$$

However, $v(B)=\delta^{-1}(B) \omega(B)[1]$; hence, the following is obtained: 


$$
Y_{t}=\delta^{-1}(B) \omega(B) X_{t-b}+N_{t}
$$

Giving room for several inputs $X_{1, t}, X_{2, t}, \ldots, X_{m, t}$, the following is obtained:

$$
\begin{gathered}
Y_{t}=v_{1}(B) X_{1, t}+\cdots+v_{m}(B) X_{m, t}+N_{t} \\
Y_{t}=\delta^{-1}(B) \omega_{1}(B) X_{1, t-b}+\cdots+\delta^{-1}(B) \omega_{m}(B) X_{m, t-b}+N_{t}
\end{gathered}
$$

where $v_{j}(B)$ is the generating function of the impulse response weights relating $X_{j, t}$ to the output. If differencing is applied to the input and output series the following is obtained:

$$
y_{t}=v_{1}(B) x_{1, t}+\cdots+v_{m}(B) x_{m, t}+n_{t} .
$$

Multiplying throughout by $X_{1, t-k}, X_{2, t-k}, \ldots, X_{m, t-k}$, in turn, taking expectations and forming the generating functions, the following is obtained:

$$
\begin{aligned}
\gamma^{x_{1} y}(B)= & v_{1}(B) \gamma^{x_{1} x_{1}}(B)+v_{2}(B) \gamma^{x_{1} x_{2}}(B)+\cdots \\
& +v_{m}(B) \gamma^{x_{1} x_{m}}(B) \\
\gamma^{x_{2} y}(B)= & v_{1}(B) \gamma^{x_{2} x_{1}}(B)+v_{2}(B) \gamma^{x_{2} x_{2}}(B)+\cdots \\
& +v_{m}(B) \gamma^{x_{2} x_{m}}(B) \\
\vdots & \\
\gamma^{x_{2} y}(B)= & v_{1}(B) \gamma^{x_{2} x_{1}}(B)+v_{2}(B) \gamma^{x_{2} x_{2}}(B)+\cdots \\
& +v_{m}(B) \gamma^{x_{2} x_{m}}(B)
\end{aligned}
$$

Putting $B=e^{-i 2 \pi f}$, the spectral equations are obtained. For the case of $m=2$, the spectral equations are

$$
\begin{aligned}
& p_{x_{1} y}(f)=H_{1}(f) p_{x_{1} x_{1}}(f)+H_{m}(f) p_{x_{1} x_{2}}(f), \\
& p_{x_{2} y}(f)=H_{1}(f) p_{x_{2} x_{1}}(f)+H_{m}(f) p_{x_{2} x_{2}}(f) .
\end{aligned}
$$

The frequency response functions $H_{1}(f)=$ $v_{1}\left(e^{-i 2 \pi f}\right), H_{2}(f)=v_{2}\left(e^{-i 2 \pi f}\right)$ can be calculated through methods outlined in the literature on spectral analysis, of which Koopmans [22] and Jenkins and Watts [23] are typical examples. The impulse response weights can be obtained by the inverse transformation as follows:

$$
v_{k}=\int_{-\frac{1}{2}}^{\frac{1}{2}} v\left(e^{-i 2 \pi f}\right) e^{i 2 \pi f} d f
$$

\section{Methodology}

The first step in the modelling involves modelling the relationship between the inputs and output of the industrial processes used as case studies in this research. In this case the periodic performance of a soap plant for the years 2009,
2010 and 2011 and periodic performance of a brewery for the periods 2006-2007, 2008-2009 and 2010-2011 were modelled. This is done to enable obtaining the COPs of the systems.

The transfer function model based on Eq. (4) was realized by a plot of the input-output data using SPSS software. After the plot, plots of the autocorrelation functions (ACF) and partial autocorrelation functions (PACF) were used to study the stationarity of the data. Differencing was used to achieve stationarity in non-stationary series. A univariate Autoregressive Integrated Moving Average (ARIMA) model was individually fitted to the input $X_{1 t}$ and output $Y_{t}$, and input $X_{2 t}$ and output $Y_{t}$ for each of the periods of the plants under study in order to, respectively, estimate prewhitened input series $\alpha_{1 t}$ and $\alpha_{2 t}$, and pre-treated output series $\beta_{1 t}$ and $\beta_{2 t}$, respectively. Calculation of the crosscorrelation functions at various lags, $\operatorname{CCF}(k)$ of $\beta_{1 t} \alpha_{1 t-k}$ and $\beta_{2 t} \alpha_{2 t-k}$, was used to identify $r, s$ and $b$ parameters of the transfer function model. On obtaining the nature of the transfer function models, the impulse response weights $v_{k}$, estimated with spectral analysis, were used to estimate the transfer function parameters. Subsequently, the transfer function parameters were combined with fuzzy logic and ANN to develop an ANFIS model used to evaluate the periodic performance of the plants under study.

ANFIS modelling began with the development of the membership functions for the input variables and the performance ratings of the output (plant performance). The membership function/values were assigned by intuition. As a sequel to the development of the membership functions and fuzzification of the input and output variables, the ANFIS was used to model the effects of the input variables on plant performances.

\subsection{The ANFIS model architecture}

Figure 2 shows the architecture of a first-order ANFIS. Sugeno Model was used for the inference system.

Assuming two rules for simplicity, the rule for the model is of this nature.

Rule 1

If $x$ is $\mathrm{A}_{1}$ and $y$ is $\mathrm{B}_{1}$ then

$$
f_{1}=p_{1} x+q_{1} y+u_{1} .
$$

Rule 2

If $x$ is $\mathrm{A}_{2}$ and $y$ is $\mathrm{B}_{2}$ then

$$
f_{2}=p_{2} x+q_{2} y+u_{2}
$$

The details of the layers of the ANFIS architecture are explained herein.

Layer 1

$O_{n, i}$ is the output of the $i$ th node of the layer $n$.

Every node $i$ in this layer is an adaptive node with a node function 


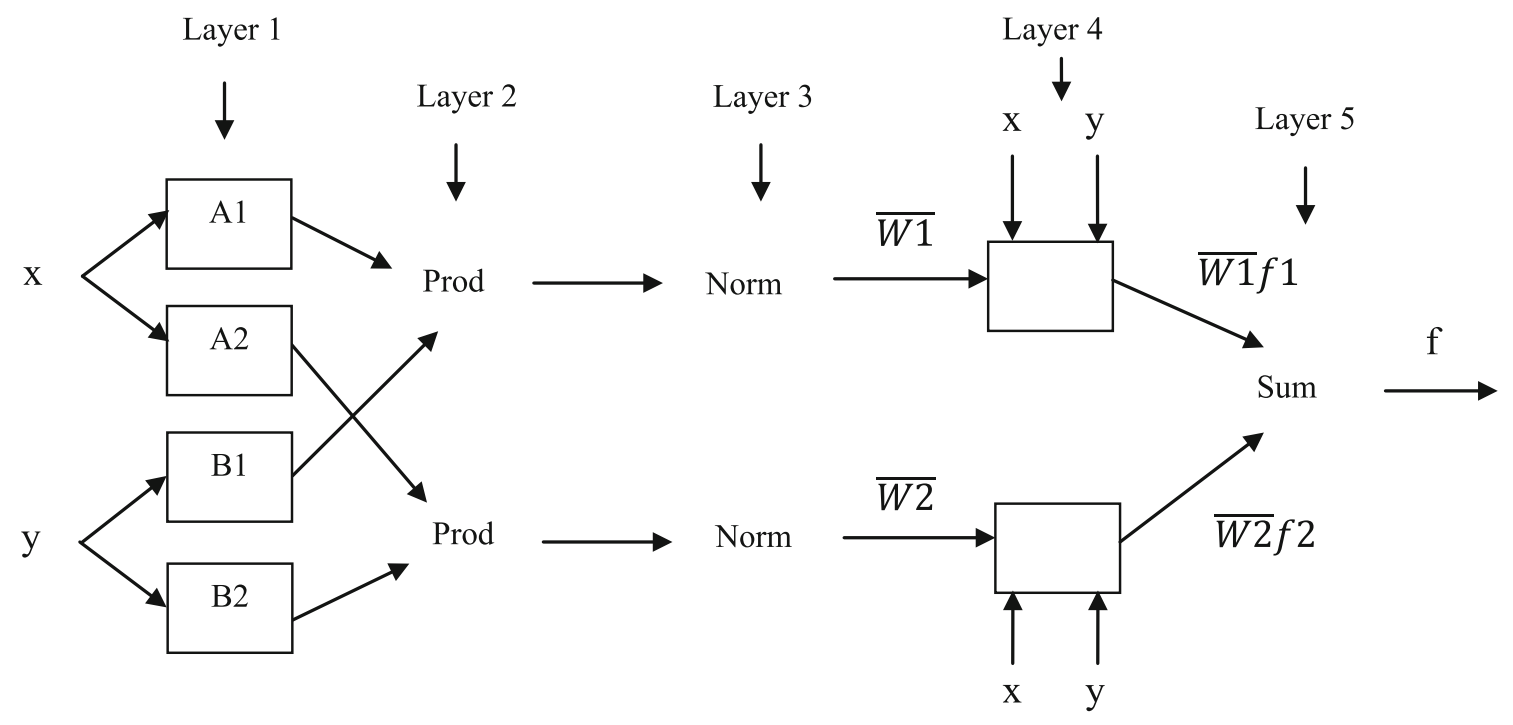

Figure 2. The ANFIS architecture.

$$
O_{1, i}=\mu_{A_{i}}(x) \quad \text { for } i=1,2
$$

and

$O_{1, i}=\mu_{B_{i-2}}(x)$ for $i=3,4$.

$x$ (or $y$ ) is the input node $i$

and $A_{i}$ (or $B_{i-2}$ ) is a linguistic variable associated with this node.

Therefore $O_{1, i}$ is the membership grade of a fuzzy set (A1, A2, B1, B2).

Layer 2

Every node in this layer is a fixed node labelled as Prod.

The output is the product of all the incoming signals:

$$
O_{2, i}=w_{i}=\mu_{A_{i}}(x) \mu_{B_{i}}(y) \quad \text { for } i=1,2 .
$$

Each node represents the fire strength of the rule.

Any other T-norm operator that perform the AND operator can be used.

Layer 3

Every node in this layer is a fixed node labelled as Norm.

The $i$ th node calculates the ratio of the $i$ th rule's firing strength to the sum of all rule's firing strengths:

$$
O_{3, i}=\bar{w}_{i}=\frac{w_{i}}{w_{1}+w_{2}} \quad \text { for } i=1,2 .
$$

Outputs are called as normalized firing strengths.

Layer 4

Every node $i$ in this layer is an adaptive node with a node function:

$$
O_{4, i}=\bar{w}_{i} f_{i}=\bar{w}_{i}\left(p_{i} x+q_{i} y+u_{i}\right)
$$

$\bar{w}_{i}$. is the normalized firing strength from layer 3; $\left\{p_{i}, q_{i}, u_{i}\right\}$. is the parameter set of this node. They are referred to as consequent parameters.
Layer 5

The single node in this layer is a fixed node labelled as Sum, which computes the overall output as the summation of all incoming signals:

$$
\text { overall output }=O_{5, i}=\sum_{i} \bar{w}_{i} f_{i}=\frac{\sum_{i} w_{i} f_{i}}{\sum_{i} w_{i}}
$$

\section{Results}

\subsection{Case study 1: brewing operations}

4.1a Transfer function modelling of the brewing operations:

The monthly raw materials consumption and the corresponding output (drink production) in the years 2006-2007 for the brewery are shown in figure 3 . The process raw material $X_{1}$ is cereal while the raw material $X_{2}$ is the additive.

(i) Analysis of the relationship between input 1 (X1) and output $(Y)$

Sequel to the plots shown in figure 3 , the data $\left(X_{1}\right.$ series) were studied for stationarity, using the plots of the ACF and PACF.

The $X_{1}$ series when analysed was found to be stationary; hence, differencing was not used. Study of the ACF and PACF in figures 4 and 5 shows that auto-regression one (AR (1)) model is the appropriate model to use.

The formula for AR (1) models [1, 24] is as follows:

$$
X_{1 t}=\theta_{0}+\emptyset_{1} X_{1 t-1}+e_{t} .
$$

However, for AR (1) models 


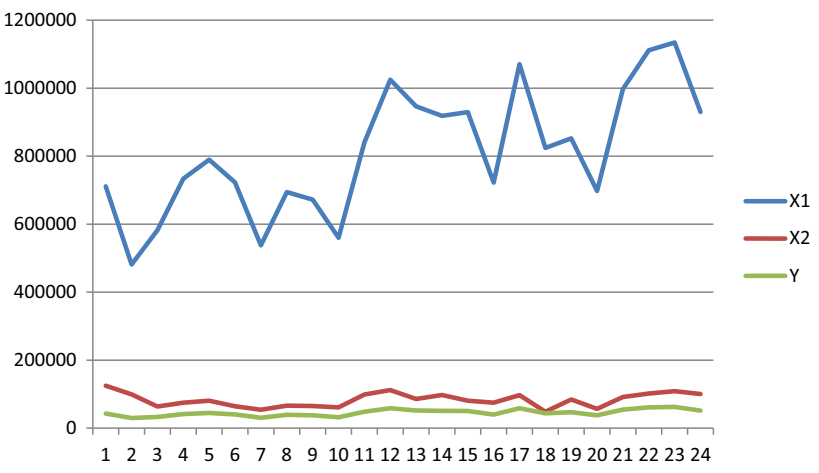

Figure 3. Weekly raw material consumption and output of the brewery.

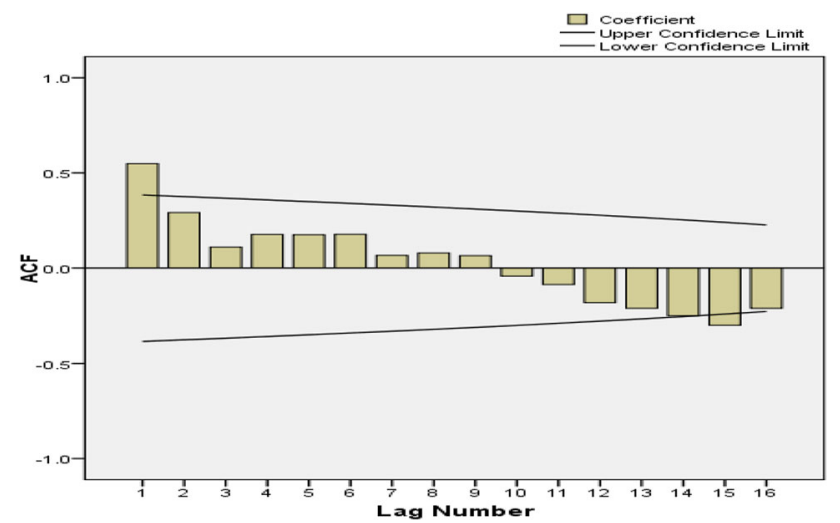

Figure 4. ACF of the input series $\left(X_{1}\right)$.

$$
\begin{aligned}
\operatorname{ACF}(1) & =\emptyset_{1}=0.549, \\
\theta_{0} & =\left(1-\emptyset_{1}\right) \mu, \\
\mu & =811883.96, \\
\theta_{0} & =(1-0.549) 811883.96, \\
\theta_{0} & =366159.66596 .
\end{aligned}
$$

Substituting the coefficients $\theta_{0}$ and $\emptyset_{1}$ into the formula for AR (1) models, the following is obtained:

$$
X_{1 t}=366159.66596+0.549 X_{1 t-1}+e_{t} .
$$

However

$$
e_{t}=\alpha_{t} .
$$

In forecasting form, Eq. (19) is transformed to the following equation:

$$
\hat{X}_{1 t}=20496.74864+0.549 X_{1 t-1} .
$$

Pre-treating the output in the same way the input is transformed, the following is obtained:

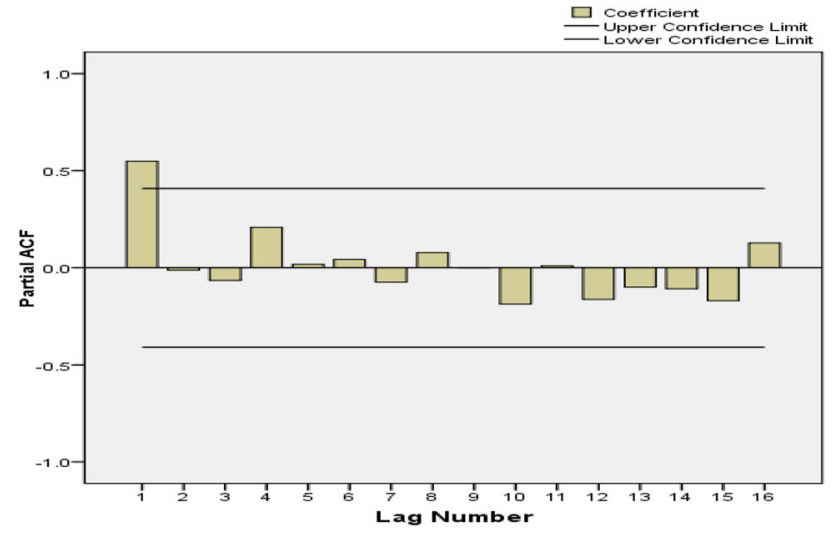

Figure 5. PACF of the input series $\left(X_{1}\right)$.

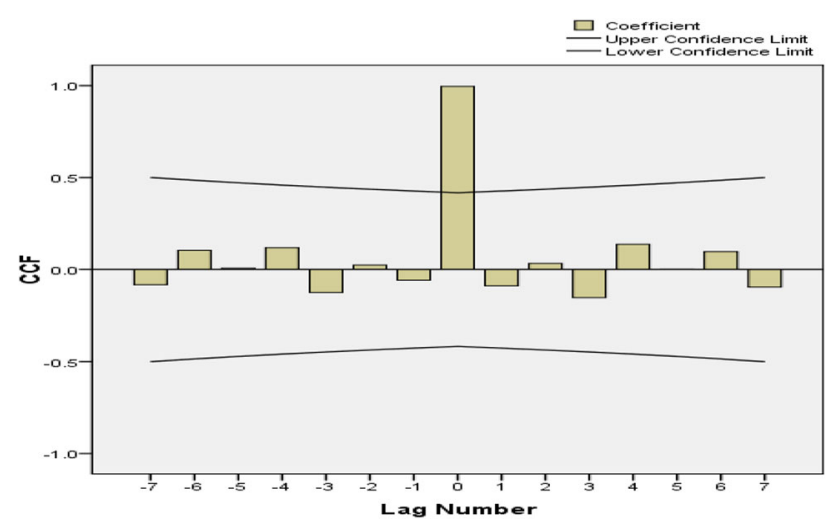

Figure 6. $\mathrm{CCF}$ of the pre-whitened series derived from the input $\left(X_{1}\right)$ and output series $(Y)$.

$$
\begin{aligned}
\emptyset_{1} & =0.549, \\
\theta_{0} & =\left(1-\emptyset_{1}\right) \mu, \\
\mu & =45447.33623, \\
\theta_{0} & =(1-0.549) 45447.33623, \\
\theta_{0} & =20496.74864, \\
Y_{t} & =20496.74864+0.549 Y_{t-1}+e_{t} .
\end{aligned}
$$

However

$$
e_{t}=\beta_{t} \text {. }
$$

In forecasting form, Eq. (22) is transformed to

$$
\hat{Y}_{t}=20496.74864+0.549 Y_{t-1} .
$$

Shown in figure 6 is the CCF between $\beta_{t}$ and $\alpha_{t}$. It has one significant $\mathrm{CCF}$ at lag zero (0). Hence, the parameters $r, s$ and $b$ of the transfer function that supports such CCF pattern are 0,0 and 0 , respectively $[1,24]$. Thus the $\mathrm{CCF}$ supports the following transfer function model:

$$
y_{t}=\omega 1_{0} x_{1 t}+N_{t} .
$$


From the Ljung-Box statistics and analysis of the residuals, the transfer function was found to have white noise residuals; hence, the noise term $\left(N_{t}\right)$ was discarded to obtain

$$
y_{t}=\omega 1_{0} x_{1 t} .
$$

As stated by Box et al [1] and DeLurgio [24]

$$
\begin{aligned}
& v 1_{0}=\omega 1_{0}, \\
& v 1_{0}=\text { impulse response for } X_{1} .
\end{aligned}
$$

However

$$
X_{1 t}-\mu_{1}=x_{1 t}
$$

and

$$
Y_{t}-\mu_{y}=y_{t} .
$$

Substituting Eq. (29) into Eq. (26), the following is obtained:

$$
Y_{t}=\mu_{y}+\omega 1_{0} x_{1 t}
$$

(ii) Analysis of the relationship between input $2\left(\mathrm{X}_{2}\right)$ and output (Y)

Carrying out a similar procedure as outlined in section $4.1 \mathrm{a}(\mathrm{i})$, the relationship between input $2\left(X_{2}\right)$ and output $(Y)$ was obtained as

$$
Y_{t}=\mu_{y}+\omega 2_{0} x_{2 t}
$$

Obtaining the transfer function models

$X_{1}$ and $Y$ have been related in section 4.1a(i) earlier, while $X_{2}$ and $Y$ were related in section 4.1a(ii). It is clear from the relationships that the transfer function relating $Y$ with $X_{1}$ and $X_{2}$ is of the form

$$
y_{t}=\omega 1_{0} x_{1 t}+\omega 2_{0} x_{2 t} .
$$

Since $y_{t}=Y_{t}-\mu_{y}, x_{1 t}=X_{1 t}-\mu_{1}$ and $x_{2 t}=X_{2 t}-\mu_{2}$,

$$
Y_{t}=\mu_{y}+\omega 1_{0}\left(X_{1 t}-\mu_{1}\right)+\omega 2_{0}\left(X_{2 t}-\mu_{2}\right) .
$$

Since

$$
v 1_{0}=\omega 1_{0} \text { and } v 2_{0}=\omega 2_{0}
$$

where

$$
\begin{aligned}
v 1_{0}= & \text { impulse response for } X_{1} \text { and } v 2_{0} \\
& =\text { impulse response for } X_{2} \\
Y_{t}= & \mu_{y}+v 1_{0}\left(X_{1 t}-\mu_{1}\right)+v 2_{0}\left(X_{2 t}-\mu_{2}\right)
\end{aligned}
$$

$v 1_{0}$ and $v 2_{0}$. were obtained by spectral analysis. Sequel to the spectral analysis and parameter optimization using genetic algorithm, the values of $v 1_{0}$. and $v 2_{0}$ as obtained were

$$
v 1_{0}=0.048234991 \text { and } v 2_{0}=0.060100632 \text {. }
$$

Hence for 2006-2007 operation of the brewery, the following transfer function was obtained

$$
\begin{aligned}
Y_{t}= & 45447.329+0.048234991\left(X_{1 t}-\mu_{1}\right) \\
& +0.060100632\left(X_{2 t}-\mu_{2}\right) .
\end{aligned}
$$

For the six years operation of the brewery, the transfer function models are given in table 1.

The COPs of the brewery for the years 2011, 2012 and 2013 are given in table 2 . As table 2 shows, the smallest raw material consumption occurred in the year 2011 while the rate of transformation of the cereals to finished drink was the biggest in the same year. The overall plant performance could be determined by ANFIS modelling.

\section{1b The ANFIS modelling of the brewing operations:}

\section{(i) Input membership functions}

The membership functions shown in figures 7 and 8 are developed for the two inputs, while the membership function shown in figure 9 is for the lag variable $b$.

The membership functions are triangular and for a typical membership function, say low input 1, the following is obtained:

$$
\mu_{\text {low }}(x)=\left\{\begin{array}{cc}
0, & x \leq 0 \\
100 x, & 0<x \leq 0.01 \\
2-100 x, & 0.01<x \leq 0.02 \\
0, & x>0.02
\end{array} .\right.
$$

Table 2. Coefficients of performance of the brewery used as case study.

\begin{tabular}{lcc}
\hline & $\begin{array}{c}\text { Coefficient of } \\
\text { performance (cereals) } \\
\omega 1_{0}\end{array}$ & $\begin{array}{c}\text { Coefficient of } \\
\text { performance (additive) } \\
\text { Year }\end{array}$ \\
\hline $2010-2011$ & 0.0489805291298761 & 0.0547027826309204 \\
$2008-2009$ & 0.0451340973377228 & 0.0746965254718585 \\
$2006-2007$ & 0.0482349914364490 & 0.0601006329059601 \\
\hline
\end{tabular}

Table 1. Transfer function models of the brewery used as case study.

\begin{tabular}{lc}
\hline Year & Transfer function model $(v(B))$ \\
\hline $2010-2011$ & $Y_{t}=64785.938+0.0489805291298761\left(X_{1 t}-\mu_{1}\right)+0.0547027826309204\left(X_{2 t}-\mu_{2}\right)$ \\
$2008-2009$ & $Y_{t}=60639.747+0.0451340973377228\left(X_{1 t}-\mu_{1}\right)+0.0746965254718585\left(X_{2 t}-\mu_{2}\right)$ \\
$2006-2007$ & $Y_{t}=45447.329+0.048234991436449\left(X_{1 t}-\mu_{1}\right)+0.0601006329059601\left(X_{2 t}-\mu_{2}\right)$
\end{tabular}




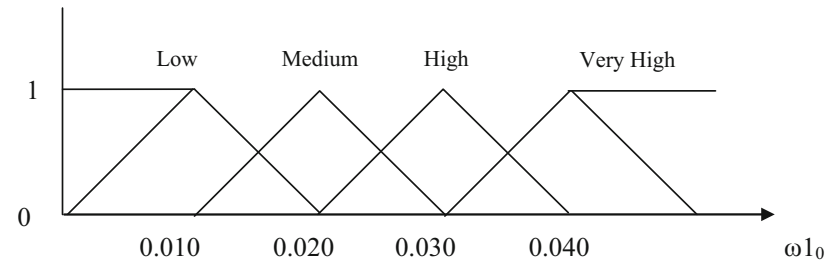

Figure 7. Membership function for coefficient of input 1 (cereal).

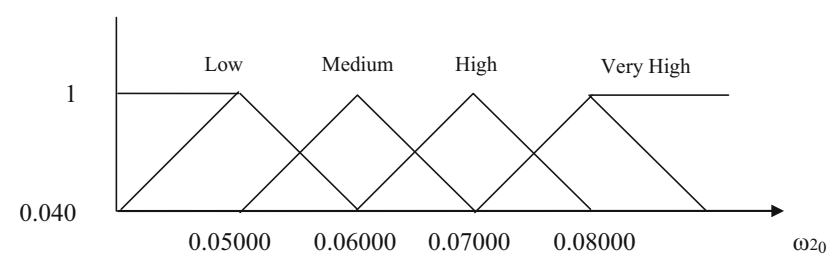

Figure 8. Membership function for coefficient of input 2 (additive).

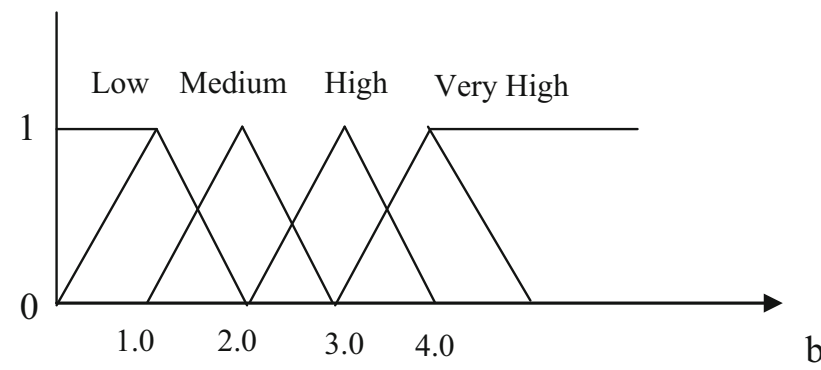

Figure 9. Membership function for lag variable, $b$.

(ii) The output membership function (performance rating)

Two types of output membership functions were used to develop two ANFIS models. The membership functions are hereby presented.

\section{Model 1 membership functions}

Poor

$$
f_{1}=10.41675 x-4.1667 y-0.0625015 .
$$

Fair

$$
f_{2}=10.41675 x-4.1667 y+0.1874985 .
$$

Good

$$
f_{3}=10.41675 x-4.1667 y+0.4374985 .
$$

Excellent

$$
f_{4}=10.41675 x-4.1667 y+0.6874985 .
$$

\section{Model 2 membership functions}

The membership functions for model two are shown in table 3 . As shown in table 3 , the membership function is a constant.
Table 3. Membership functions for model 2.

\begin{tabular}{lc}
\hline Linguistic variable & Output \\
\hline Poor & $f_{1}=0.25$ \\
Fair & $f_{2}=0.5$ \\
Good & $f_{3}=0.75$ \\
Excellent & $f_{4}=1$ \\
\hline
\end{tabular}

(iii) ANFIS modelling results for the brewery operations

The two inputs to the brewing process and the lag variable altogether constitute the inputs to the fuzzy inference system, denoted by $x$ and $y$, respectively. Since the lag is the same in all the periods under consideration, it was ignored in the ANFIS modelling; hence, two inputs were effectively used. In order to train and test the adaptive neural network models, a sample input-output of the fuzzy inference system shown in table 4 was used.

Fuzzy logic rules were developed for the ANFIS models. Some of the rules are the following.

If cereal is low AND additive is very high THEN performance rating is poor.

If cereal is low AND additive is low THEN performance rating is fair.

Altogether, 16 rules were developed. The ANFIS models were trained and tested with the input-output data in table 4 and the rules to model the Sugeno fuzzy inference process. The results obtained from the modelling are shown in tables 5 and 6.

\subsection{Case study 2: soap production process}

\section{2a Transfer function modelling of the soap production process:}

Here, the soap production process, which was modelled as a MISO process, was used. Figure 10 shows the weekly raw materials consumption and the corresponding output (soap production) in the year 2011 for the soap plant. The raw material $X_{1}$ is soap chips while the raw material $X_{2}$ is the additive.

Following a similar procedure as outlined in section 4.1a for the brewery, the following transfer function models shown in table 7 were obtained for the three years operation of the soap plant.

The COPs of the soap production plant for the years 2011, 2012 and 2013 are given in table 8. As table 8 shows, raw material consumption was the least in the year 2011 while the rate of transformation of the soap chips to finished soap was the highest in the same year. The overall plant performance could be determined by ANFIS modelling.

$4.2 \mathrm{~b}$ The ANFIS modelling of the soap production operations:

Using similar methods as outlined in section 4.2a for brewing, ANFIS was used to model the soap production operations with very interesting results presented here. 
Table 4. Input-output table.

\begin{tabular}{lccc}
\hline Input 1 $(x)$ & Input 2 $(y)$ & Model 1 output $(f)$ & Model 2 output $(f)$ \\
\hline 0.038 & 0.05 & 0.625 & 0.75 \\
0.038 & 0.06 & 0.333333 & 0.5 \\
0.038 & 0.07 & 0.041666 & 0.25 \\
0.038 & 0.08 & $-1 \mathrm{E}-06$ & 0.25 \\
0.042 & 0.05 & 0.916667 & 1 \\
0.042 & 0.06 & 0.375 & 0.5 \\
0.042 & 0.07 & 0.083333 & 0.25 \\
0.042 & 0.08 & 0.041666 & 0.25 \\
0.046 & 0.05 & 0.958334 & 1 \\
0.046 & 0.06 & 0.666667 & 0.75 \\
0.046 & 0.07 & 0.375 & 0.5 \\
0.046 & 0.08 & 0.083333 & 0.25 \\
0.05 & 0.05 & 1.000001 & 1 \\
0.05 & 0.06 & 0.708334 & 0.75 \\
0.05 & 0.07 & 0.666667 & 0.75 \\
0.05 & 0.08 & 0.125 & 0.25 \\
\hline
\end{tabular}

Table 5. Models performance for brewery operations.

\begin{tabular}{lc}
\hline ANFIS model & Testing error \\
\hline Model 1 & 0 \\
Model 2 & 0.000000035 \\
\hline
\end{tabular}

ANFIS modelling results for case study 2: soap production operations

The two inputs to the soap production system and the lag variable altogether constitute the inputs to the fuzzy inference system denoted by $x$ and $y$, respectively. Since the lag is the same in all the periods under consideration, it was ignored in the ANFIS modelling; hence two inputs were effectively used. In order to train and test the adaptive neural network models, a sample input-output of the fuzzy inference system shown in table 10 was used.

Fuzzy logic rules were developed for the ANFIS models. Some of the rules are:

If soap chips are low AND additive is very high THEN performance rating is poor.

If soap chips are low AND additive is low THEN performance rating is fair.

Altogether, 16 rules were developed. The ANFIS models were trained and tested with the input-output data in

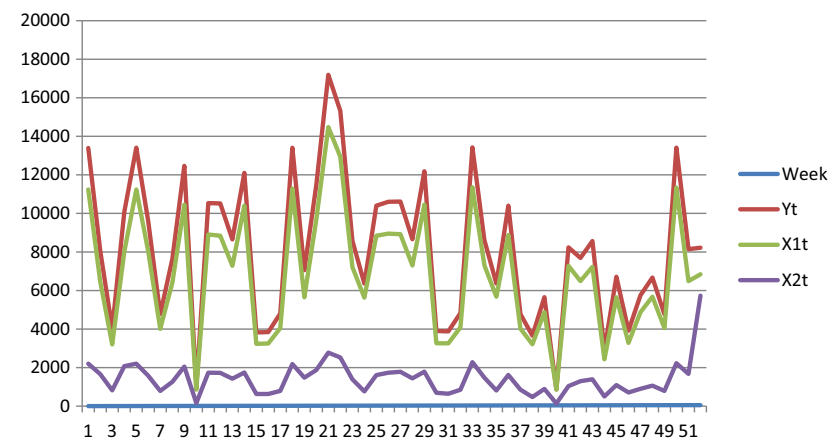

Figure 10. Weekly raw material consumption and output of the soap plant.

table 9 and the rules to model the Sugeno fuzzy inference process. The results obtained from the modelling are shown in tables 10 and 11 .

\section{Discussion}

For case study 1, the low level of errors, $0 \%$ and $0.000000035 \%$ as shown in table 6 , indicates that the ANFIS model predicted the outputs almost perfectly. From the results, though model 2 had the least error as shown in table 7 , model 1 seems to have a better approximation to the performance rating $\lambda$ obtained from a fuzzy model using the MAMDANI inference process as shown in table 2. As shown in table 7 there is a general consensus among the models that performance was the worst in the period 2008-2009 and the best in 2010-2011. Table 12 shows the correlation of ANFIS and MAMDANI results. As shown in table 12, model 2 has a better correlation with MAMDANI model in the modelling of brewery operations done in case study 1 . However, model 1 has better correlation with MAMDANI model in case study 2 .

In this study, zero-order systems were considered. The general equation for transfer function models according to Eq. (2) is

$$
Y_{t}=\delta^{-1}(B) \omega(B) X_{t-b}+N_{t}
$$

In zero-order systems, $\delta$ is 0 ; in first-order systems equation (2) is transformed into

Table 6. Comparison of ANFIS and MAMDANI predictions for brewing operations.

\begin{tabular}{|c|c|c|c|c|c|}
\hline Year & $\begin{array}{c}\text { Coefficient of } \\
\text { performance (cereals) } \\
\omega 1_{0}\end{array}$ & $\begin{array}{c}\text { Coefficient of } \\
\text { performance (additive) } \\
\omega 2_{0}\end{array}$ & $\begin{array}{l}\text { Performance rating from } \\
\text { MAMDANI FIS } \lambda\end{array}$ & $\begin{array}{c}\text { ANFIS model } 1 \\
\text { prediction } \lambda\end{array}$ & $\begin{array}{c}\text { ANFIS model } 2 \\
\text { prediction } \lambda\end{array}$ \\
\hline 2010-2011 & 0.04898 & 0.05470 & 0.810 & 0.940 & 0.970 \\
\hline 2008-2009 & 0.04513 & 0.07470 & 0.381 & 0.200 & 0.354 \\
\hline 2006-2007 & 0.04823 & 0.06010 & 0.786 & 0.826 & 0.887 \\
\hline
\end{tabular}


Table 7. Transfer function models of the soap plant used as case study.

\begin{tabular}{lc}
\hline Year & Transfer function model $(v(B))$ \\
\hline 2011 & $Y_{t}=\mu_{y}+1.143727\left(X_{1 t}-\mu_{1}\right)+0.7043\left(X_{2 t}-\mu_{2}\right)$ \\
2012 & $Y_{t}=\mu_{y}+0.77586\left(X_{1 t}-\mu_{1}\right)+3.4413\left(X_{2 t}-\mu_{2}\right)$ \\
2013 & $Y_{t}=\mu_{y}+0.799972\left(X_{1 t}-\mu_{1}\right)+2.219733\left(X_{2 t}-\mu_{2}\right) 2.219733\left(X_{2 t}-\mu_{2}\right)$ \\
\hline
\end{tabular}

Table 8. Coefficients of performance of the soap plant used as case study.

\begin{tabular}{lcc}
\hline Year & $\begin{array}{c}\text { Coefficient of performance } \\
\text { (soap chips) } \omega 1_{0}\end{array}$ & $\begin{array}{c}\text { Coefficient of performance } \\
\text { (additive) } \omega 2_{0}\end{array}$ \\
\hline 2011 & 1.143727 & 0.7043 \\
2012 & 0.77586 & 3.4413 \\
2013 & 0.799972 & 2.219733 \\
\hline
\end{tabular}

Table 9. Input-output table.

\begin{tabular}{lccc}
\hline Input 1 $(x)$ & Input 2 $(y)$ & Model 1 output $(f)$ & Model 2 output $(f)$ \\
\hline 0.5 & 1 & 0.375 & 0.5 \\
0.5 & 2 & 0.083333 & 0.25 \\
0.5 & 3 & 0.041666 & 0.25 \\
0.5 & 4 & 0 & 0.25 \\
1 & 1 & 0.666667 & 0.75 \\
1 & 2 & 0.375 & 0.5 \\
1 & 3 & 0.083333 & 0.25 \\
1 & 4 & 0.041666 & 0.25 \\
1.5 & 1 & 0.958334 & 1 \\
1.5 & 2 & 0.666667 & 0.75 \\
1.5 & 3 & 0.375 & 0.5 \\
1.5 & 4 & 0.083333 & 0.25 \\
2 & 1 & 1 & 1 \\
2 & 2 & 0.958334 & 1 \\
2 & 3 & 0.666667 & 0.75 \\
2 & 4 & 0.375 & 0.5 \\
\hline
\end{tabular}

Table 10. Models performances.

\begin{tabular}{lc}
\hline ANFIS model & Testing error \\
\hline Model 1 & 0 \\
Model 2 & 0.000004365 \\
\hline
\end{tabular}

$$
Y_{t}=\omega(B) X_{t-b}+N_{t}
$$

The possible models of zero-order systems where fuzzy logic and ANFIS could be used include the following.

\section{SISO systems}

The model equations could be

$$
y_{t}=\omega_{0} x_{t-b}
$$

where $b$ is not constant. Here, $\omega_{0}$ and $b$ are fuzzified.

In the second case, for SISO system, the model is of this nature:

$$
y_{t}=\omega_{0} x_{t-b}+N_{t}
$$

where $b$ may or may not be a constant. Here $\omega_{0}, b$ and $N_{t}$ are fuzzified.

The linguistic variables for $N_{t}$ could for example be low noise, medium noise, high noise or very high noise. It should be noted that $b$ can be fuzzified only if it is not a constant.

\section{MISO systems}

The model equations could be

$$
y_{t}=\omega 1_{0} x_{1 t-b}+\omega 2_{0} x_{2 t-b}+\cdots+\omega n_{0} x_{n t-b}
$$

where $b$ is variable or a constant. Here $\omega i_{0}(i=1,2, \ldots, n), b$ and $N_{t}$ are fuzzified. It should again be noted that $b$ can be fuzzified only if it is not a constant.

In the second case for MIMO system, the model is of this nature:

$$
y_{t}=\omega 1_{0} x_{1 t-b}+\omega 2_{0} x_{2 t-b}+\cdots+\omega n_{0} x_{n t-b}+N_{t}
$$

where $b$ is variable or a constant. Here $\omega i_{0}(i=1,2, \ldots, n), b$ and $N_{t}$ are fuzzified.

The linguistic variables for $N_{t}$ could for example be low noise, medium noise, high noise or very high noise. It should be noted that $b$ can be fuzzified only if it is not a constant.

Table 11. Comparison of ANFIS and MAMDANI predictions for soap production operations.

\begin{tabular}{cccccc}
\hline Year & $\begin{array}{c}\text { Coefficient of } \\
\text { performance (cereals) } \omega 1_{0}\end{array}$ & $\begin{array}{c}\text { Coefficient of performance } \\
\text { (additive) } \omega 2_{0}\end{array}$ & $\begin{array}{c}\text { Performance rating from } \\
\text { MAMDANI FIS } \lambda\end{array}$ & $\begin{array}{c}\text { ANFIS model 1 } \\
\text { prediction } \lambda\end{array}$ & $\begin{array}{c}\text { ANFIS model 2 } \\
\text { prediction } \lambda\end{array}$ \\
\hline 2011 & 1.143727 & 0.7043 & 0.761 & 0.763 & 0.822 \\
2012 & 0.77586 & 3.4413 & 0.250 & 0.046 & 0.250 \\
2013 & 0.799972 & 2.219733 & 0.395 & 0.216 & 0.367 \\
\hline
\end{tabular}


Table 12. Correlation of ANFIS models with MAMDANI model.

\begin{tabular}{lcc}
\hline & Case study 1 & Case study 1 \\
Model & Correlation coefficient & $\begin{array}{c}\text { Correlation coefficient } \\
R\end{array}$ \\
\hline Model 1 & 0.995608443 & 0.998748337 \\
Model 2 & 0.997213573 & 0.996466751 \\
\hline
\end{tabular}

Generally, material wastes and low-quality materials are problems often encountered in production processes. One of the primary goals of process control is to improve quality and reduce wastes. Transfer function neuro-fuzzy modelling described herein, an excellent process monitoring and control tool, would actually help improve production operations in practice. By so doing, goods/products are produced more economically, boosting the profitability of firms engaged in the production of goods.

Production processes should be very efficient so as to boost the profitability of businesses and enhance better utilization of scarce raw materials. Efficient processes also help conserve energy and protect the environment. In order to ensure that the production processes and systems, e.g., soap production process and brewing, remain efficient there must be continuous observation, monitoring and control of the process.

Better monitoring and control technique measures the efficiency and process performance better and if religiously adopted and implemented by production and process managers would lead to improved processes.

This research successfully introduced a better method for performance evaluation, assessment and monitoring of brewing and soap production processes, typical MISO processes. The method uses transfer function and ANFIS to measure efficiency, monitor and control process performance better.

This new promising method would help ensure better utilization of raw materials in brewing and soap production, provide better diagnostic tool to monitor and control process performance in brewing and soap production, as well as act as an excellent quality control tool.

In general, the major advantages of this method are as outlined as follows:

a. Greater accuracy in the periodic measurement of efficiency,

b. Statistically robust and sound efficiency measurements,

c. Better and more accurate plant/equipment fault diagnosis and superior aid to predictive and preventive maintenance and

d. Complex simultaneous assessment of raw material usage, quality, production efficiency and production time under a single platform.

Implementing this new system requires expertise, skill and tact. The first step towards the implementation of this new system is to ensure accurate record of operations data. The new system requires a lot of statistical analysis; hence, the organization is expected to keep extensive and detailed records of operations data. Practical implementation of the new system requires either pilot or parallel conversion depending on the nature and size of the industrial organization.

To implement the new system in big industrial organizations with several plants, pilot conversion is advocated. In pilot conversion the system is implemented from plant to plant under the guidance of experts such as Industrial Engineers, Systems Engineers, Operations Researchers or Management Consultants. Under the pilot scheme, operations managers are trained on the new system and when they have sufficiently gained experience on the workings of the new system the trainers would withdraw and allow the managers to implement the new system in other plants within the organization. If the managers do not have sufficient expertise, the consultants would manage the operations of the new system, as well as its implementation and operation in other plants within the organization.

For small single plant industrial organizations, parallel conversion should be used. In parallel conversion, the new system runs side by side with the old system while the managers are gradually trained on the operations of the new system. The old system is expected to be phased out after some period of time to be determined by the consultant. The expertise of the managers determines on whose responsibility the overall management of the new system lies. If the managers do not have sufficient expertise, the consultant would be saddled with the responsibility of the overall management of the new system.

\section{Conclusion}

Modelling multivariate processes is quite difficult and challenging. The complexity of multivariate analysis increases as the number of inputs increases, making the modelling task quite daunting. In this work only two input single output process as typified by the brewing and soap production processes studied herein were considered. The result of this study is very significant because the researcher has been able to model the complex interaction between raw material quality and operations efficiency to determine plant performance rating using neuro-fuzzy modelling and transfer function. Of more significance would be the result as the number of interacting inputs increases. The transfer function neuro-fuzzy modelling method developed in this paper is a statistically sound and robust method of assessing, evaluating and monitoring the performance of MISO systems. This method could be extended to multi-input multi-output (MIMO) systems and single-input multi-output (SIMO) systems. 


Abbreviations
ACF autocorrelation function
PACF partial autocorrelation function

\section{List of sysmbols}

$k \quad$ lag variable

$\beta t \quad$ pre-treated output series

$\alpha_{t} \quad$ pre-whitened input series

$v(B)$ transfer function

$B$ backshift operator

$Y_{t} \quad$ process output at time $t$

$X_{t} \quad$ process input at time $t$

$y_{t} \quad$ differenced output series

$x_{t} \quad$ differenced input series

$\hat{Y}_{t} \quad$ output forecast

$\hat{X}_{t} \quad$ input forecast

$a_{t} \quad$ error term/white noise

$v_{k} \quad$ impulse response weight at lag $k$

$h \quad$ ACF-PACF lag

$q$ order of moving average operator

$p \quad$ order of autoregressive operator

$d \quad$ number of differencing

$\theta \quad$ autoregressive operator

$\boldsymbol{\varphi}$ autoregressive operator

$\Xi$ coefficient of output variable of differential equation

$H$ coefficient of input variable of differential equation

$X$ covariance function

$b \quad$ transfer function lag

$\omega$ difference equation variable for input

$\delta \quad$ difference equation variable for output

$r \quad$ order of the output series

$s \quad$ order of the input series

$S \quad$ sample standard deviation

$\sigma \quad$ population standard deviation

$\rho$ autocorrelation function

$\gamma \quad$ cross correlation function

$\mu \quad$ mean

\section{References}

[1] Box G E P, Jenkins G M and Reinsel G C 2008 Time Series Analysis Forecasting and Control. USA: McGraw-Hill

[2] Igboanugo A C and Nwobi-Okoye C C 2012 Transfer function modelling as a tool for solving manufacturing system dysfunction. Res. J. Appl. Sci. Eng. Technol. 4(23): 4948-4953

[3] Igboanugo A C and Nwobi-Okoye C C 2011 Production process capability measurement and quality control using transfer functions. J. Nigerian Assoc. Math. Phys. 19(1): 453-464

[4] Lai P 1979 Transfer function modelling relationship between time series variables. Concepts and Techniques in Modern Geography (CATMOG), London School of Economics, No. 22
[5] Nwobi-Okoye C C 2017 Transfer function based performance assessment of power distribution facilities: a case study of distribution transformers. J. Electr. Syst. Inf. Technol. https://dx.doi.org/10.1016/j.jesit.2016.12.001

[6] Nwobi-Okoye C C and Igboanugo A C 2012 Performance evaluation of hydropower generation system using transfer function modelling. Int. J. Electr. Power Energy Syst. 43(1): $245-254$

[7] Nwobi-Okoye C C and Igboanugo A C 2015 Performance appraisal of gas based electric power generation system using transfer function modelling. Ain Shams Eng. J. https://dx.doi. org/10.1016/j.asej.2014.11.006

[8] Zadeh L 1965 Fuzzy sets. Inf. Control 8: 338-353

[9] Ertuğrul İ and Karakaşoğlu N 2009 Performance evaluation of Turkish cement firms with fuzzy analytic hierarchy process and TOPSIS methods. Expert Syst. Appl. 36(1): 702-715

[10] Seçme N, Bayrakdaroğlu A and Kahraman C 2009 Fuzzy performance evaluation in Turkish banking sector using analytic hierarchy process and TOPSIS. Expert Syst. Appl. 36(9): 11699-11709

[11] Chen S 1996 Evaluating weapon systems using fuzzy arithmetic operations. Fuzzy Sets Syst. 77(3): 265-276

[12] Yang C C and Chen B S 2004 Key quality performance evaluation using fuzzy AHP. J. Chin. Inst. Ind. Eng. 21(6): 543-550

[13] Sadiq R, Al-Zahrani M A, Sheikh A K and Husain T 2004 Performance evaluation of slow sand filters using fuzzy rulebased modelling. Environ. Model. Softw. 19(5): 507-515

[14] Yeh C H, Deng H and Chang Y H 2000 Fuzzy multicriteria analysis for performance evaluation of bus companies. Eur. J. Oper. Res. 126(3): 459-473

[15] Wu D D 2009 Performance evaluation: an integrated method using data envelopment analysis and fuzzy preference relations. Eur. J. Oper. Res. 194(1): 227-235

[16] Cheng C H and Lin Y 2002 Evaluating the best main battle tank using fuzzy decision theory with linguistic criteria evaluation. Eur. J. Oper. Res. 142(1): 174-186

[17] Lin C T, Chiu H and Tseng Y H 2006 Agility evaluation using fuzzy logic. Int. J. Prod. Econ. 101(2): 353-368

[18] Ross T J 2009 Fuzzy logic with engineering applications, 2nd edn. Chichester, England: Wiley

[19] Sandhu P S and Singh H 2007 Automatic reusability appraisal of software components using neuro-fuzzy approach. Int. J. Inf. Technol. 3(3): 209-215

[20] Hosoz M, Ertunc H M and Bulgurcu H 2011 An adaptive neuro-fuzzy inference system model for predicting the performance of a refrigeration system with a cooling tower. Expert Syst. Appl. 38: 14148-14155

[21] Wang W Q, Golnaraghi M F and Ismail F 2004 Prognosis of machine health condition using neuro-fuzzy systems. Mech. Syst. Signal Process. 18(4): 813-831

[22] Koopmans L H 2003 The spectral analysis of time series. Amsterdam, Netherlands: Elsevier

[23] Jenkins G M and Watts D G 1968 Spectral analysis and its applications. New York, USA: McGraw-Hill

[24] DeLurgio S A 1998 Forecasting principles and applications, 3rd edn. New York, USA: McGraw-Hill 